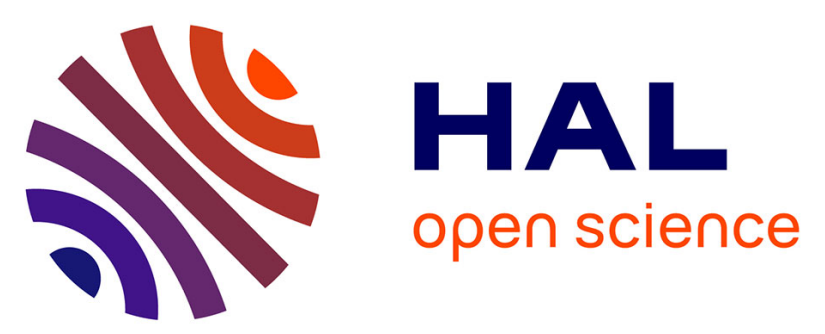

\title{
Intermolecular electron transfer in two-iron superoxide reductase: a putative role for the desulforedoxin center as an electron donor to the iron active site.
}

Florence Bonnot, Simon Duval, Murielle Lombard, Julien Valton, Chantal Houée-Levin, Vincent Nivière

\section{To cite this version:}

Florence Bonnot, Simon Duval, Murielle Lombard, Julien Valton, Chantal Houée-Levin, et al.. Intermolecular electron transfer in two-iron superoxide reductase: a putative role for the desulforedoxin center as an electron donor to the iron active site.. Journal of Biological Inorganic Chemistry, 2011, 16 (6), pp.889-98. 10.1007/s00775-011-0788-5 . hal-01075287

\section{HAL Id: hal-01075287 \\ https://hal.science/hal-01075287}

Submitted on 7 Jan 2015

HAL is a multi-disciplinary open access archive for the deposit and dissemination of scientific research documents, whether they are published or not. The documents may come from teaching and research institutions in France or abroad, or from public or private research centers.
L'archive ouverte pluridisciplinaire HAL, est destinée au dépôt et à la diffusion de documents scientifiques de niveau recherche, publiés ou non, émanant des établissements d'enseignement et de recherche français ou étrangers, des laboratoires publics ou privés. 


\title{
Inter-molecular electron transfer in two iron superoxide
}

\section{reductase. A putative role for the desulforedoxin center as an}

\section{electron donor to the iron active site}

\author{
Florence Bonnot $^{\mathrm{a}}$, Simon Duval ${ }^{\mathrm{a}}$, Murielle Lombard ${ }^{\mathrm{b}}$, Julien Valton ${ }^{\mathrm{a}}$, \\ Chantal Houée-Levin $^{c}$, Vincent Nivière ${ }^{\mathrm{a} \bowtie}$
}

${ }^{\text {a }}$ Laboratoire de Chimie et Biologie des Métaux, iRTSV-CEA Grenoble/CNRS/Université Joseph Fourier, 17 Avenue des Martyrs, 38054 Grenoble Cedex 9, France. ${ }^{\mathrm{b}}$ Laboratoire de Chimie et Biochimie Pharmacologiques et Toxicologiques, UMR 8601, Université René Descartes Paris 5, 45 rue des Saints-Pères, 75270 Paris Cedex 06, France . ${ }^{c}$ laboratoire de Chimie Physique, UMR8000 CNRS/Université Paris-Sud and CNRS, Bâtiment 350, Centre Universitaire 91405 Orsay Cedex, France.

$\S$ Present adress: Cellectis bioresearch, 102 avenue Gaston Roussel 93230 Romainville, France.

Laboratoire de Chimie et Biologie des Métaux, iRTSV-CEA Grenoble/CNRS/Université Joseph Fourier, 17 Avenue des Martyrs, 38054 Grenoble Cedex 9, France. Tel: 334387891 09; Fax: 33438789124 ; E.mail: vniviere@cea.fr

List of abbreviations. SOR: superoxide reductase; SOD: superoxide dismutase; Dx: desulforedoxin; Rub: rubredoxin; Fpr: NADPH-flavodoxin-oxidoreductase from E. coli; ROS: reduced oxygen species. 


\section{ABSTRACT}

Superoxide reductase (SOR) is a superoxide detoxification system present in some microorganisms. Its active site consists of an unusual mononuclear iron center with a FeN4S1 coordination which catalyzes the one-electron reduction of superoxide to form hydrogen peroxide. Different classes of SORs have been described depending on the presence of an additional rubredoxin-like, desulforedoxin iron center, whose function has remained unknown until now. In this work, we investigated the mechanism of the reduction of the SOR iron active site using the NADPH-flavodoxin-oxidoreductase from Escherichia coli, which was previously shown to efficiently transfer electrons to the Desulfoarculus baarsii SOR. When present, the additional rubredoxin-like iron center could function as an electronic relay between cellular reductases and the iron active site for superoxide reduction. This electron transfer was mainly inter-molecular, between the rubredoxin-like iron center of one SOR and the iron active site of another SOR. These data provide the first experimental evidence for a possible role of the rubredoxin-like iron center in the superoxide detoxifying activity of SOR.

\section{KEY WORDS}

Superoxide reductase; electron transfer; rubredoxin; desulforedoxin; oxidative stress. 


\section{INTRODUCTION}

Oxidative stress represents one of the major challenges that organisms living in contact with oxygen have to face $[1,2]$. It corresponds to the formation of reactive oxygen species (ROS) during aerobic metabolisms, such as superoxide radical $\left(\mathrm{O}_{2}^{\bullet-}\right)$, hydrogen peroxide $\left(\mathrm{H}_{2} \mathrm{O}_{2}\right)$ and the hydroxyl radical $\left(\mathrm{HO}^{\bullet}\right)$, which are highly toxic for cells. Cells express very efficient antioxidant systems which detoxify these species $[1,2]$. In the case of the superoxide radical, only two classes of enzymes able to detoxify it have been described: the superoxide dismutase (SOD) [3], expressed in almost all cells living in contact with oxygen, and the more recently discovered superoxide reductase (SOR) which has been found in some microaerophilic and anaerobic bacteria [4-9]. The presence of antioxidant systems in anaerobic bacteria, in particular those living in close contact with aerobic biotopes, allows them to survive when they are transiently or accidentally exposed to oxygen [10].

At the difference of SODs, SORs do not catalyze the dismutation reaction of superoxide, but a one-electron reduction of superoxide to produce $\mathrm{H}_{2} \mathrm{O}_{2}$, without formation of $\mathrm{O}_{2}$ (eq. 1).

$$
\left.\mathrm{O}_{2}^{\bullet-}+1 \mathrm{e}^{-}+2 \mathrm{H}^{+} \rightarrow \mathrm{H}_{2} \mathrm{O}_{2} \quad \text { (eq. } 1\right)
$$

The SOR active site is located at the surface of the protein and consists of a mononuclear iron center, named center II, pentacoordinated in its ferrous state by four nitrogen atoms from histidine residues in an equatorial plane and one sulfur atom from a cysteine residue in an axial position [11-14]. It displays a high redox potential of about +300 $\mathrm{mV}$ (vs. NHE) at neutral $\mathrm{pH}$ and remains mainly in a reduced form in the presence of air [1518]. Center II has an open coordination site, which represents the site where superoxide binds and is reduced by the ferrous iron to $\mathrm{H}_{2} \mathrm{O}_{2}$ (eq. 2) [16-21]. The resulting ferric SOR iron site 
can be regenerated to the ferrous active form by cellular electron donors (eq. 3), allowing catalytic turn-over for the reduction of superoxide.

$$
\begin{aligned}
& \mathrm{O}_{2}^{\bullet-}+\mathrm{SOR}-\mathrm{Fe}^{2+}+2 \mathrm{H}^{+} \rightarrow \mathrm{H}_{2} \mathrm{O}_{2}+\mathrm{SOR}-\mathrm{Fe}^{3+} \\
& \left.\mathrm{SOR}-\mathrm{Fe}^{3+}+1 \mathrm{e}^{-} \rightarrow \mathrm{SOR}-\mathrm{Fe}^{2+} \quad \text { (eq. } 3\right)
\end{aligned}
$$

Two main classes of SORs have been described, associated with the presence of an additional N-terminal domain, which chelates an additional mononuclear iron center. When present, this iron center, named center I, is chelated by four cysteine residues in a distorted tetrahedral similar to arrangement of rubredoxin, in a fold very similar to that found for the small electron transfer protein desulforedoxin [22]. Its redox potential is more negative than that of the iron active site, with a value of about $+100 \mathrm{mV}$ (vs. NHE) at neutral $\mathrm{pH}[15,17$, 18]. SORs having this additional iron center, e.g. the enzymes from Desulfovibrio desulfuricans [11], Desulfoarculus baarsii [5, 14] and Desulfovibrio vulgaris [21], are named 2Fe-SOR whereas those having only the iron active site, like the enzymes from Pyrococcus furiosus [4, 12], Archaeoglobus fulgidus [18] and Treponema pallidum [13] are named 1FeSORs.

In order to better understand the cellular antioxidant properties of SOR, the identification of its electron donor(s) (eq. 3) represents an important challenge. In particular, it is not known yet whether SOR uses specific electron donors to reduce superoxide or if the enzyme has the capability to use a wide panel of electron sources, favoring a superoxide detoxification activity independent of a specific electron transfer pathway. Whereas cellular reductase enzymes directly involved in the SOR reduction pathway have not been identified yet, two small electron transfer proteins rubredoxin (Rub) [23-26] and desulforedoxin (Dx) [27] have been shown to efficiently transfer electrons to the ferric SOR active site. For 
rubredoxin, these results are consistent with the fact that in several bacterial genomes, sor and $r u b$ genes have been found to be encoded within the same operon.

In the case of $2 \mathrm{Fe}-\mathrm{SOR}$, the function of iron center I has remained unknown up to now. Deletion of the iron center I in the D. vulgaris Hildenborough enzyme was shown to have no effect on the reactivity of the ferrous iron center II with superoxide [16]. It was proposed that center I could serve as an electronic relay between the cellular reductases and the catalytic iron site but the distance of $22 \AA$ between iron center I and center II $[11,14]$ was considered too long for efficient intramolecular electron transfer [28]. A well conserved tyrosine residue in 2Fe-SOR (Y115 in D. baarsii) located between center I and center II, at 10 $\AA$ from iron center II, was proposed to act as an electronic relay between the two iron centers (Figure 1) [29], but up to now no studies have investigated these hypotheses.

In this work, we investigated the function of iron center I as an electronic relay between a reductase enzyme and iron center II. We used the NADPH-flavodoxinoxidoreductase Fpr from $E$. coli that has previously been shown to reduce rapidly the $D$. baarsii $2 \mathrm{Fe}-\mathrm{SOR}[30]$. We demonstrated that iron center I could efficiently transfer electrons from the Fpr reductase to the SOR active site, acting as an inter-molecular electronic relay between two molecules of SOR. These data provide the first experimental evidence for a role of iron center I in the superoxide detoxifying activity of $2 \mathrm{Fe}-\mathrm{SOR}$. 


\section{MATERIALS AND METHODS}

Materials. For pulse radiolysis experiments, sodium formate and buffers were of the highest quality available (Prolabo Normatom or Merck Suprapure). Oxygen was from ALPHA GAZ. Its purity was higher than $99.99 \%$. Water was purified using an Elga Maxima system (resistivity $18.2 \mathrm{M} \Omega$ ). $\mathrm{K}_{2} \mathrm{IrCl}_{6}$ was from Strem Chemical Inc. Kinetic traces were analyzed using a Levenberg-Marquardt algorithm from the Kaleidagraph ${ }^{\circledR}$ software package (Synergy Software)

Site-directed mutagenesis and purification of SORs. Four primers were designed for PCRbased site-directed mutagenesis to create C13S and Y115A D. baarsii SOR mutants. For the C13S SOR mutant, primer 1 (5'-CAAATGTGAGGTTTCECGGAAACATCGTCG-3') and primer 2 (5'-CGACGATGTTTCCGGAAACCTCACATTTG-3') were used. For the Y115A SOR mutant, primer 3 (5'-GTCGTGGCCCGCGAAGCGTGCAACATCCACGGC-3' and primer 4 (5'-GCCGTGGATGTT GCACGCTTCGCGGGCCACGAC-3') were used. In each primer, the mutations of interest are underlined. Mutagenesis was carried out on the pMJ25 plasmid [31] with the QuikChange site-directed mutagenesis kit from Stratagene. The mutations were verified by DNA sequencing. The resulting plasmids, pDbC13S and pDbY115A, were transformed in an E. coli BL21 (DE3) strain. The recombinant E. coli cells were grown in M9 minimum media supplemented with glucose, casamino acid, $\mathrm{FeCl}_{3}$, ampicillin and IPTG, as reported for the wild-type SOR [5]. The C13S and Y115A SOR mutants were purified to homogeneity by anion exchange and gel exclusion chromatographies, as reported for the wild-type SOR [19]. The yields of purification from $1 \mathrm{~L}$ of culture of the wild-type, C13S and Y115A SOR mutants are $10 \mathrm{mg}, 2 \mathrm{mg}$ and $9 \mathrm{mg}$, respectively. 
The two purified mutant proteins appeared to be homogeneous, as seen by SDS-PAGE analysis, and found to be as stable as the wild-type protein. Electrospray mass spectrometry analysis on the purified mutants showed major species at 14,010 Da for the C13S SOR mutant and at $13,935 \mathrm{Da}$ for the Y115A SOR mutant, corresponding for both mutants to the molecular mass expected from the amino acid sequence, without the $\mathrm{N}$-terminal Met residue. Protein concentration was determined using the Bio-Rad protein assay reagent. Metallation of the iron sites was verified by atomic absorption spectroscopy, with a value of 1 iron atom per polypeptide chain for the C13S SOR mutant and 2 iron atoms per polypeptide chain for the Y115A SOR mutant (data not shown).

Purification of the recombinant D. baarsii rubredoxin. Culture of E. coli BL21 (DE3) transformed with the pMJ26 plasmid, encoding for the D. baarsii rubredoxin gene [31], were grown aerobically overnight at $37{ }^{\circ} \mathrm{C}$ in a Luria-Bertani (LB) medium complemented with 0.1 $\mathrm{mM} \mathrm{FeCl}{ }_{3}, 100 \mu \mathrm{g} / \mathrm{ml}$ ampicillin and $1 \mathrm{mM}$ IPTG. After sonication of the cells and ultracentrifugation at 45,000 rpm during $90 \mathrm{~min}$ (Beckman 50.2 Ti rotor), the supernatant was loaded onto an anion exchange column Q-Sepharose (Amersham Biosciences). The proteins were eluted with a $0-0.5 \mathrm{M} \mathrm{NaCl}$ linear gradient, in $10 \mathrm{mM}$ Tris- $\mathrm{HCl} \mathrm{pH}$ 7.6. The fractions with $\mathrm{Abs}_{491 \mathrm{~nm}} / \mathrm{Abs}_{280 \mathrm{~nm}}$ ratio $>0.2$ were loaded onto a gel filtration Superdex 75 column (Amersham Biosciences), equilibrated with $10 \mathrm{mM}$ Tris- $\mathrm{HCl} \mathrm{pH}$ 7.6. The eluted fractions with $\mathrm{Abs}_{491 \mathrm{~nm}} / \mathrm{Abs}_{280 \mathrm{~nm}}$ ratio of 0.4 contained pure rubredoxin, as judged by SDS-PAGE.

Oxidation and reduction of SORs. For the C13S SOR mutant, fully reduced SOR was obtained by treatment of the protein with a slight molar excess of sodium ascorbate. Fully oxidized SORs were obtained by treatment of the proteins with a slight molar excess of $\mathrm{K}_{2} \mathrm{IrCl}_{6}$. The sodium ascorbate and $\mathrm{K}_{2} \mathrm{IrCl}_{6}$ treated proteins were washed with a Microcon 10 micro concentrator using $10 \mathrm{mM}$ Tris- $\mathrm{HCl} \mathrm{pH}$ 7.6. 
Pulse radiolysis. Pulse radiolysis measurements were performed as described elsewhere [17, 19]. Briefly, free radicals were generated by irradiation of $\mathrm{O}_{2}$-saturated aqueous protein solutions $(100 \mu \mathrm{M})$, in $2 \mathrm{mM}$ of Tris- $\mathrm{HCl}$ buffer, $\mathrm{pH} 7.6,10 \mathrm{mM}$ sodium formate, with 0.2 $1.0 \mu \mathrm{s} 4 \mathrm{MeV}$ electrons pulses at the linear accelerator at the Curie Institute, Orsay, France. Superoxide anion was generated during the scavenging by formate of the radiolytically produced hydroxyl radical, $\mathrm{HO}^{\circ}$, as previously described [17]. The dose varied linearly with the pulse length, for instance a dose of $c a .5$ Gy per pulse $(0.2 \mu$ s long) resulted in $c a .2 .8 \mu \mathrm{M}$ of $\mathrm{O}_{2}{ }^{\bullet}$. Reactions were followed spectrophotometrically using a Xenon-Mercury or a tungsten lamp in $2 \mathrm{~cm}$ path length cuvettes, at $20{ }^{\circ} \mathrm{C}$. In order to avoid photochemical reactions associated with the reaction intermediates [19], a cut-off filter cutting all wavelengths below $425 \mathrm{~nm}$ was positioned between the lamp and the cuvette.

Stopped-Flow Experiments. The kinetics of reduction of center II by center I was determined at $25{ }^{\circ} \mathrm{C}$ under anaerobic conditions, using a Bio-Logic stopped-flow SFM 400 apparatus equipped with a MOS 450 optical system. Deaerated solutions of fully reduced SOR and fully oxidized SOR were loaded into the two separate drive syringes of the stopped-flow apparatus, under anaerobic conditions. The stopped-flow mixing process was carried out with a 1:1 (v/v) proportion. The absorbance changes were monitored at $644 \mathrm{~nm}$.

NADPH-flavodoxin-oxidoreductase assays. The recombinant NADPH-flavodoxinoxidoreductase (Fpr) from E. coli was purified as reported in [32]. The specific activity of the purified Fpr was measured by the reduction of horse heart cytochrome $c$. The reduction of SOR proteins by Fpr was conducted under anaerobic conditions in a glove box under $\mathrm{N}_{2}$ atmosphere at room temperature, in the presence of $25 \mathrm{mM}$ Tris- $\mathrm{HCl}, \mathrm{pH}$ 7.6, $3.5 \mathrm{mg} / \mathrm{L}$ of Fpr and $800 \mu \mathrm{M}$ of NADPH. Fpr was added to initiate the reaction. The initial rates of reduction of center I and center II were measured by the decrease in absorbances at 503 and $644 \mathrm{~nm}$, respectively. 
The NADPH:superoxide oxidoreductase assays were carried out under aerobic conditions at room temperature, in a $1 \mathrm{ml}$ spectrophotometric cuvette, in the presence of $10 \mathrm{mM}$ Tris- $\mathrm{HCl}$, pH 7.6, $200 \mu \mathrm{M}$ NADPH, 500 units/ml catalase, $500 \mu \mathrm{M}$ hypoxanthine, $1 \mu \mathrm{M}$ of Fpr and 1 $\mu \mathrm{M}$ of SOR $[23,30]$. Catalase was added in order to remove hydrogen peroxide produced by the SOR reaction and by the xanthine/xanthine oxidase superoxide generating system. After $50 \mathrm{~s}$, a known quantity of xanthine oxidase that produced a flux of superoxide of $22 \mu \mathrm{M} / \mathrm{min}$ [5] was added to initiate the reaction. The rate of NADPH oxidation was measured by the decrease of the absorbance at $340 \mathrm{~nm}\left(\varepsilon_{340 \mathrm{~nm}}=6.22 \mathrm{mM}^{-1} \mathrm{~cm}^{-1}\right)$.

Analytical experiments. Absorbance measurements were made using a Varian Cary spectrophotometer, in a $1 \mathrm{~cm}$ path length cuvette. For center II $\mathrm{pK}_{\mathrm{a}}$ determination, the following buffers $(10 \mathrm{mM})$ were used: $\mathrm{pH}$ 6.0, Mes; $\mathrm{pH} 7.6,8.0$ and 8.5, Tris-HCl; $\mathrm{pH} 8.9$ and 9.8, glycine- $\mathrm{NaOH}$. Electrospray ionization mass spectra were obtained on a PerkinElmer Sciex API III+ triple quadrupole mass spectrometer equipped with a nebulizer-assisted electrospray source operating at atmospheric pressure. Samples were in $10 \mathrm{mM}$ ammonium acetate. 


\section{RESULTS}

\section{Characterization of the D. baarsii C13S and Y115A SOR mutants}

Two mutants of SOR from $D$. baarsii were constructed in order to investigate the role of center I in the reduction of iron center II. First, cysteine 13, which provides one of the four sulfur ligands of iron center I, was mutated into a serine. Second, to investigate a possible role of tyrosine 115 as an electron relay between center I and center II (Figure 1), this residue was mutated into an alanine.

The recombinant C13S and Y115A SOR mutants were purified to homogeneity as reported for the wild-type SOR. The purified C13S SOR mutant was found to be a homodimer, as reported for the wild-type protein $[5,14]$ (data not shown). The air isolated C13S SOR mutant presented a UV-visible spectrum with no absorption bands at $503 \mathrm{~nm}$ and $370 \mathrm{~nm}$, showing the absence of iron center I (Figure S1, A). A weak absorption band at 644 $\mathrm{nm}$ was visible, indicating that about $10 \%$ of iron center II of purified protein was in oxidized form. When the mutant was treated with a slight molar excess of $\mathrm{K}_{2} \mathrm{IrCl}_{6}$, the absorption band at $644 \mathrm{~nm}$, characteristic of SOR iron center II [5], strongly increased to a maximum value (Figure S1, A). The band at $644 \mathrm{~nm}$ shifted to $560 \mathrm{~nm}$ at basic $\mathrm{pH}$, as reported for the wildtype protein (Figure S1, B), with a pKa value of $8.30 \pm 0.05$ (Figure S1, B), slightly more acidic than that reported for the wild-type protein (value of 9.0, [17]). The extinction coefficient for the $644 \mathrm{~nm}$ band of the C13S SOR mutant in acidic solution was found to be very close to that reported for the wild-type SOR $\left(1.9 \mathrm{mM}^{-1} \mathrm{~cm}^{-1}\right)$ [17].

The reactivity of the C13S SOR mutant with superoxide was studied by pulse radiolysis, as reported for the wild-type protein [19]. At pH 7.6, when $8 \mu \mathrm{M}$ of $\mathrm{O}_{2}^{\bullet-}$ was reacted with $100 \mu \mathrm{M}$ of the reduced C13S SOR mutant, two reaction intermediates $\mathrm{T} 1$ and $\mathrm{T} 2$ were formed, as observed for the wild-type protein [19], corresponding to the formation of 8 
$\mu \mathrm{M}$ of mutant in its oxidized form as final reaction product (data not shown). At wavelengths around $600 \mathrm{~nm}$, the absorbances of TI and T2 were found to be similar to those observed for the wild-type protein reacted with the same concentration of superoxide [19] (data not shown). At $\mathrm{pH} 7.6$, the rate constants determined for the formation of $\mathrm{T} 1\left(k_{1}\right.$, second order with respect to SOR and $\left.\mathrm{O}_{2}{ }^{\bullet-}\right)$, for the formation of $\mathrm{T} 2\left(k_{2}\right.$, first order) and for the formation of the final oxidized SOR ( $k_{3}$, first order) were found to be $0.9 \pm 0.1 \times 10^{9} \mathrm{M}^{-1} \mathrm{~s}^{-1}, 290 \pm 60 \mathrm{~s}^{-1}$ and $100 \pm 38 \mathrm{~s}^{-1}$, respectively. These values are almost identical to those reported for the reaction of wild-type SOR with $\mathrm{O}_{2}^{\bullet-}$ at $\mathrm{pH} 7.6$ [19]. Altogether these data showed that the lack of iron center I in the D. baarsii C13S SOR mutant did not significantly affect the folding of iron center II and its reactivity with superoxide, as has been previously reported for the D. vulgaris Hildenborough C13S SOR mutant [16].

The purified recombinant Y115A SOR mutant was found to be a homodimer, with the same UV-visible spectroscopic properties in its isolated and fully oxidized forms as the wildtype protein [5] (data not shown). The second order rate constant for the reaction of the Y115A SOR mutant with superoxide $\left(k_{l}\right)$ was determined by pulse radiolysis at $\mathrm{pH}$ 7.6, with a value of $1.7 \pm 0.5 \times 10^{9} \mathrm{M}^{-1} \mathrm{~s}^{-1}$, very close to that reported for the wild-type protein [16] (data not shown). These data indicated that the Y115A SOR mutant folded properly and that this mutation did not affect the general properties of the two iron sites of SOR.

\section{Reduction of wild-type and SOR mutant proteins by Fpr}

Fpr is a flavoprotein from $E$. coli with FAD as cofactor. It uses NADPH to reduce various electron acceptors such as flavodoxin or ferredoxin in vivo or ferricyanide and cytochrome c in vitro [32]. Fpr has previously been shown to efficiently transfer electrons to the $D$. baarsii $2 \mathrm{Fe}-\mathrm{SOR}[30]$ and was used here to study the mechanism of SOR reduction. As shown in Figure 2, in the presence of a catalytic amount of Fpr and NADPH as electron 
donor, both $D$. baarsii SOR centers I and II could be fully reduced. This was observed in the semi-reduced form of $\mathrm{SOR}^{1}$, where center I was reduced by Fpr and in the fully oxidized SOR, where both centers I and II were reduced by Fpr (Figure 2A). Interestingly, with the fully oxidized SOR, the total reduction of the two iron centers exhibited two steps. This is illustrated in Figure 2B, where the reduction kinetics of the two iron centers was observed at 503 and $644 \mathrm{~nm}$. At these wavelengths, both oxidized centers absorb, but they have different extinction coefficients. The breakdown of slope observed 90 seconds after initiation of reaction clearly illustrates the sequential reduction process, in which center II is totally reduced in a first phase $\left(\varepsilon_{644 \mathrm{~nm}}=1.9 \mathrm{mM}^{-1} \mathrm{~cm}^{-1}, \varepsilon_{503 \mathrm{~nm}}=0.7 \mathrm{mM}^{-1} \mathrm{~cm}^{-1}\right)$, followed by the full reduction of center $I$ in a second phase $\left(\varepsilon_{503 \mathrm{~nm}}=4.4 \mathrm{mM}^{-1} \mathrm{~cm}^{-1}, \varepsilon_{644 \mathrm{~nm}}=0.6 \mathrm{mM}^{-1} \mathrm{~cm}^{-1}\right)$.

The kinetics of reducing both iron centers by Fpr was investigated as a function of SOR concentration (Figure 3). The initial velocities for the reduction of both iron centers were determined in the fully oxidized SOR, at $644 \mathrm{~nm}$ for center II in the first reduction phase, as seen in the lower trace of Figure 2B, and at $503 \mathrm{~nm}$ for center I in the second reduction phase, as seen in the upper trace of Figure $2 \mathrm{~B}$. The initial velocity for the reduction of iron center I was also determined in the semi-reduced SOR at $503 \mathrm{~nm}$, and was found to be identical to that determined in the fully oxidized SOR (data not shown). Kinetics of center I and II reduction at varying SOR concentrations exhibited a dependence which fit with a Michaelis-Menton equation, allowing determination of maximal velocity $\left(V_{\max }\right)$ and $K_{m}$ values (Figure 3 ). The $V_{\max }$ value for center II reduction by Fpr appeared to be significantly higher than for of the reduction of center I, with values of $1.8 \pm 0.2$ and $1.2 \pm 0.1 \mu \mathrm{M} \mathrm{s}^{-1}$ for center II and center I, respectively. The $K_{m}$ values associated with the reduction of the two iron centers were found to be very similar, with values of $48 \pm 11$ and $61 \pm 15 \mu \mathrm{M}$ for center II and center I,

\footnotetext{
${ }^{1}$ The semi-reduced form of SOR corresponds to the air-isolated protein, where center I is ferric and center II ferrous.
} 
respectively. These data suggest that prior to the reduction of the SOR iron centers by Fpr, the formation of Fpr-SOR complex(es) occur, in agreement with a Michaelis-Menten model.

The reduction of the oxidized C13S SOR mutant by Fpr in the presence of NADPH was studied as described previously for the wild-type protein (Figure 3). At a concentration of $125 \mu \mathrm{M}$ C13S mutant, the highest concentration tested, the initial reduction rate of center II was about 30 times lower than that observed for the wild-type protein (Figure 3). This result shows that Fpr is not able to efficiently transfer its electrons to center II in the absence of center I. Such a low electron transfer rate was also observed for the SOR from Treponema pallidum, which naturally lacks center I [13]. Comparable to the C13S SOR mutant, the oxidized form of SOR from T. pallidum is poorly reduced by Fpr (Figure 3).

The reduction of the oxidized Y115A SOR mutant by Fpr in the presence of NADPH was studied as described above for the wild-type protein. Similarly to what was observed for the wild-type protein, the Y115A SOR mutant exhibited a sequential process for the reduction of its two iron centers (data not shown). The $V_{\max }$ and $K_{m}$ values determined for the reduction of the Y115A iron centers I by Fpr were found to be $1.3 \pm 0.1 \mu \mathrm{M} \mathrm{s}^{-1}$ and $75 \pm 12 \mu \mathrm{M}$, respectively (Figure S2). The $V_{\max }$ and $K_{m}$ values determined for the reduction of the Y115A iron center II by Fpr were found to be $2.0 \pm 0.2 \mu \mathrm{M} \mathrm{s}^{-1}$ and $66 \pm 15 \mu \mathrm{M}$, respectively (Figure S2). These values for both center I and center II were found to be very similar to those found for the wild-type protein (Figure 3).

\section{Electron transfer between center I and II}

As observed above, since Fpr is not able to directly reduce center II, the reduction of this center must arise from an electron transfer from center I. As shown in Figure 4A, in order to investigate the ability of center I to transfer electron to center II, equimolar concentrations of fully reduced wild-type SOR and fully oxidized wild-type SOR were mixed. This UV- 
visible spectrum was recorded immediately after mixing. The spectrum showed the complete formation of the semi-reduced SOR, where center I was fully oxidized and center II fully reduced (Figure 4A). These data show that center II has been fully reduced by center I. When the same experiments were carried out with the Y115A SOR mutant, identical spectra to those shown on Figure 4A for the wild-type protein were obtained (data not shown).

When the same amount of fully reduced wild-type SOR was mixed with fully oxidized C13S SOR mutant, the UV-visible spectrum recorded immediately after mixing showed a full reduction of C13S SOR center II mutant, together with a complete oxidation of wild-type SOR center I (Figure 4B). When the same amount of fully oxidized wild-type SOR was mixed with fully reduced C13S SOR mutant, the UV-visible spectrum recorded immediately after the mixing showed no reduction of the wild-type SOR center I (data not shown).

These experiments showed that center I of SOR has the ability to transfer one electron to center II of another SOR by an inter-molecular process. The rate of this inter-molecular electron transfer from center I to center II was measured by stopped-flow experiments under anaerobic conditions, using similar experimental conditions to those of Figure 4A. As shown in Figure 5, the reduction of center II was followed at $644 \mathrm{~nm}$, after mixing equimolar amounts of fully reduced SOR with fully oxidized SOR. The data fitted well to a hyperbolic equation describing a bimolecular mechanism in which the initial concentrations of both reactants were equal. A second-order rate constant for the electron transfer between center I and center II was calculated, with a value of $7.0 \pm 0.1 \times 10^{6} \mathrm{M}^{-1} \mathrm{~s}^{-1}$ at $\mathrm{pH} 7.6$ and $25^{\circ} \mathrm{C}$. This value is in the range of that determined for electron transfer between rubredoxins and SORs $[23,24]$. 


\section{Rubredoxin can replace iron center I as electron donor to iron center II}

The function of rubredoxin as an electron relay between Fpr and iron center II was tested on the C13S SOR mutant. The rubredoxin from D. baarsii was overexpressed in E. coli and purified to homogeneity (Materials and Methods). As shown in Table 1, the presence of 5 $\mu \mathrm{M}$ rubredoxin from $D$. baarsii or from Clostridium pasteurianum fully restored the ability of Fpr to efficiently reduce iron center II of the C13S SOR mutant. On the other hand, rubredoxin did not improve the reduction rate of center II in the wild-type SOR. Cytochrome $\mathrm{c}$ from horse heart could also induce the reduction of C13S SOR ferric center II mutant, albeit with lower efficiency than rubredoxins (Table 1). These data show that rubredoxin can play a similar function to that of iron center I as an electron relay between Fpr and iron center II.

The role of iron center I in SOR catalysis was further investigated under turn-over conditions, where superoxide was continuously generated by the xanthine-xanthine oxidase system and Fpr used as a source of electrons in the presence of NADPH. As previously described, oxidation of NADPH can be specifically associated with turnovers of SOR with superoxide $[23,30]$. As shown in Figure 6, the rate of NADPH:superoxide oxidoreductase activity for the wild-type SOR was determined to be $9.4 \mu \mathrm{M}$ NADPH oxidized per min. The C13S mutation decreased the NADPH:superoxide oxidoreductase activity of SOR by a factor of 2. When $5 \mu \mathrm{M}$ rubredoxin from $D$. baarsii were added, the NADPH:superoxide oxidoreductase activity of the C13S SOR mutant recovered full activity compared to the wildtype SOR, whereas the wild-type SOR was not affected by the addition of rubredoxin. This shows that the presence of center $\mathrm{I}$ in SOR stimulates the catalytic reduction of $\mathrm{O}_{2}^{\bullet-}$. However, the smaller effect of the C13S mutation on NADPH:superoxide oxidoreductase activity observed here, compared to what was observed for the reduction of SOR by Fpr (Figure 3), could result from the consumption of NADPH being partially rate-limited by superoxide production, as previously noted [30]. 


\section{DISCUSSION}

The presence and the function of an additional iron center (center I) in one class of SORs have been the matter of debate and up to now the role of center I has remained undetermined. The distance of $22 \AA$ between center I and center II within a subunit or $32 \AA$ between center I of one subunit and center II of the other in the homo-dimeric enzyme (Figure 1), was considered at first glance to be too long to allow efficient intra-molecular electron transfer between these two iron centers. Thus, a role for center I as an electronic relay between reductase enzymes and the iron active site of SOR was excluded. In addition, deletion of iron center I in $2 \mathrm{Fe}-\mathrm{SORs}$ was shown to have no effect on the reactivity of ferrous iron center II with superoxide (eq. 2), as observed with the D. vulgaris SOR [16] and here with the enzyme from $D$. baarsii. These results discard any structural role of center I in $2 \mathrm{Fe}-$ SORs and consequently it was thought that center I could be involved in other cellular activities, other than $\mathrm{O}_{2}^{\bullet-}$ detoxification.

In this work, we demonstrated that, contrary to what was previously thought, iron center I is involved in SOR activity and could function as an inter-molecular electron relay between cellular reductases and iron center II. Indeed our data suggest that the electron transfer mechanism is mainly inter-molecular between iron center I of SOR and iron center II of another SOR. Such an electron transfer function for center I could improve SOR detoxification activity in some cellular contexts, as discussed below.

Several lines of evidence support an electron transfer process between centers I and II in the $2 \mathrm{Fe}-\mathrm{SOR}$ from $D$. baarsii. In this study, we used the Fpr reductase from E. coli as an electron source. Fpr was previously reported to efficiently transfer electrons to SOR from $D$. baarsii, and could contribute to the catalytic detoxification activity of SOR when its gene is heterologously expressed in E. coli [5, 31]. 
When center I is present (wild-type protein), Fpr efficiently reduces both iron centers, with a comparable $k_{c a} / K_{m}$ value $\left(4 \times 10^{5} \mathrm{M}^{-1} \mathrm{~s}^{-1}\right)$ and an almost identical $K_{m}$ value (Figure 3). Since the two iron centers exhibit very different structures and surroundings $[11,14]$, different $K_{m}$ values would have been expected if Fpr could form Michaelis complexes with each of the two iron centers prior to electron transfer. Interestingly, in the absence of center I, Fpr could not efficiently reduce iron center II of SOR, unless an electron carrier like rubredoxin was added. This was demonstrated by the fact that SORs from T. pallidum and the C13S SOR mutant from $D$. baarsii, both lacking iron center I but having a similar fully functional iron center II, are poorly reduced by Fpr (Figure 3). These data suggest that in the wild-type SOR protein, center I is the site where Fpr interacts and transfers its electrons. According to this scheme, a rapid electron transfer step between center I and center II should occur. This is demonstrated in Figures 4 and 5, where a specific oxidation of iron center I of SOR is observed in the presence of the oxidized form of center II of another SOR (wild-type or C13S SOR mutant). The rate constant corresponding to the electron transfer between center I and center II $\left(7.0 \times 10^{6} \mathrm{M}^{-1} \mathrm{~s}^{-1}\right)$ is about ten times faster than the $k_{c a t} / K_{m}$ value found for the reduction of iron center I by Fpr. This indicates that the electron transfer process between the two iron centers is not rate-limiting in the overall reduction process of center II by Fpr. Finally, the sequential mechanism observed for the reduction of SOR in Figure 2 is thermodynamically consistent with such an electron transfer. Indeed, center II has a higher redox potential than center I, therefore full reduction of center II occurs before the accumulation of reduced center I.

The bi-molecular process associated with the data of Figure 5 suggests an intermolecular mechanism for electron transfer between center I of SOR and the center II of another SOR, as illustrated in Scheme 1. Indeed, our data gave no evidence of an intramolecular process between both iron centers. Accordingly, the rate of $7.0 \times 10^{6} \mathrm{M}^{-1} \mathrm{~s}^{-1}$ for 
electron transfer between center I and center II is in the range of that determined for intermolecular electron transfer between rubredoxins and SORs, as shown in the case of the $D$. vulgaris and A. fulgidus proteins [23, 24].

Although the prediction of rate constants for intra-molecular electron transfer within a protein is far from trivial, it might be interesting to attempt a rough estimation of such a rate when associated with a tunneling effect between two redox centers located at $22 \AA$ distance, as in SOR. Several values of intra-molecular electron transfer rates by tunneling were measured for well-defined protein systems $[28,33]$. The literature reports rates ranging from 1 to $100 \mathrm{~s}^{-1}$ for electron transfer at $22 \AA$ distance $[28,33]$. Although the validity of such estimation has to be taken with caution, the comparison with our data suggests that an intramolecular electron transfer with a rate constant in this range could be competitive. As a matter of fact, the half-life for the bi-molecular electron transfer process measured under our conditions is $7 \mathrm{~ms}$ (Figure 5), whereas intra-molecular electron transfer rates between 1 and $100 \mathrm{~s}^{-1}$ (uni-molecular process) would have half-lives ranging between 7 and $700 \mathrm{~ms}$. In this study, we could not experimentally determine whether such an intra-molecular electron transfer would take place in SOR. Because of the low extinction coefficients associated with both iron centers, investigations of electron transfer kinetics at SOR concentrations below 20 $\mu \mathrm{M}$ would be very imprecise with stopped-flow. However, the rate constant range (1-100 s $\left.{ }^{-1}\right)$ suggests that the intra-molecular reaction might be competitive with the second order process described in Scheme 1 at low SOR concentrations.

Because of the above considerations, it would be difficult to suggest the possible involvement of tyrosine 115 in an intra-molecular electron transfer between the two iron centers of SOR. However, our data show that in the presence of a reductase enzyme like Fpr, the absence of tyrosine 115 does not affect overall electron transfer from center I to center II. 
This suggests that if tyrosine 115 could somehow favor an intra-molecular electron transfer, it is not essential for the reduction of center II.

In conclusion, we have shown that center I could function as an electron transfer relay between cellular reductases and center II, mainly by an inter-molecular mechanism involving two different molecules of SOR. However, a slow intra-molecular electron transfer mechanism, in particular at low SOR concentration, cannot be totally ruled out.

In bacteria where SOR is naturally expressed, rubredoxin [23-27] and desulforedoxin [27] have been the only SOR electron donors identified so far. Whereas the specific involvement of desulforedoxin in an electron transport chain remains to be documented, in the case of sulfate reducing bacteria, rubredoxin is thought to act as an electron relay between the NADH:rubredoxin oxidoreductase (Nro) and several metalloproteins involved in ROS detoxification [10]. This is the case of SOR, but also of rubrerythrin (Rbr), involved in hydrogen peroxide elimination through its peroxidase activity [7] and rubredoxin:oxygen oxidoreductase (Roo) [34], an oxygen reductase that decreases the oxygen concentration within the cell. The detoxifying enzymes SOR, Rbr and Roo could then appear to be in competition for their electron donor rubredoxin. Since SOR, Rbr and Roo act in a complementary way to detoxify ROS [10], such a situation is rather intriguing, considering the necessity for cells to efficiently detoxify ROS. However, since a large number of organisms encoding $2 \mathrm{Fe}$-sor or $1 \mathrm{Fe}$-sor genes do not contain $\mathrm{rub}$ or $d x$ genes, other electron transfer pathways other than those involving rubredoxin should exist in bacteria encoding SOR.

Our data show that the Fpr enzyme can transfer electrons to the SOR active site in the absence of rubredoxin, through a specific interaction with iron center I. Although fpr does not appear to be encoded in the bacterial genome containing sor, it is possible that any reductase 
unable to directly and efficiently transfer electrons to iron center II, can still serve as an efficient electron donor to SOR as long as it can reduce iron center I. In this aspect, our data illustrate the fact that the presence of iron center I could allow SOR to use a larger panel of reductases, for instance those that are not able to reduce SOR in the absence of rubredoxin. As mentioned above, rubredoxin must deal with several different partners, the ability of SOR to use several alternative electron sources could favour its detoxification activity. These properties might confer a selective advantage to cells encoding $2 \mathrm{Fe}-\mathrm{SOR}$ genes compared to those encoding $1 \mathrm{Fe}-\mathrm{SOR}$ genes.

\section{ACKNOWLEDGEMENTS}

We thank Dr Jean-Marc Moulis for providing us rubredoxin from Clostridium pasteurianum and Dr Vincent Favaudon for kind assistance in pulse radiolysis experiments. VN and SD acknowledge support from the Agence Nationale de la Recherche, programme physique et chimie du vivant 2008. We thank the language center of the University René Descartes and Dr Sam Shen for proofreading the manuscript. 


\section{REFERENCES}

1. Winterbourn CCC (2008) Nat Chem Biol 4:278-286

2. Imlay JA (2008) Ann Rev Biochem 77:755-776

3. Fridovich I (1995) Annu Rev Biochem 64:97-112

4. Jenney FE, Verhagen MFJM, Cui X, Adams MWW (1999) Science 286:306-309

5. Lombard M, Fontecave M, Touati D, Nivière V (2000) J Biol Chem 275:115-121

6. Nivière V, Fontecave M (2004) J Biol Inorg Chem 9:119-123

7. Kurtz DM Jr (2006) J Inorg Biochem 100:679-693

8. Pereira AS, Tavares P, Folgosa F, Almeida RM, Moura I, Moura JJG (2007) Eur J Inorg Chem 18:2569-2581

9. Pinto AF, Rodrigues JV, Teixeira M (2010) Biochim Biophys Acta 1804:285-297

10. Wildschut JD, Lang RM, Voordouw JK, Voordouw G (2006) J Bacteriol 188:6253-6260

11. Coelho A, Matias P, Fülöp V, Thompson A, Gonzalez A, Carrondo MA (1997) J Biol Inorg Chem 2:680-689

12. Yeh AP, Hu Y, Jenney FE Jr, Adams MWW, Rees DC (2000) Biochemistry 39:249924508

13. Santos-Silva T, Trincao J, Carvalho AL, Bonifacio C, Auchère F, Raleiras P, Moura I, Moura JJG, Romao J (2006) J Biol Inorg Chem 11:548-558

14. Katona G, Carpentier P, Nivière V, Amara P, Adam V, Ohana J, Tsanov N, Bourgeois D (2007) Science 316:449-453

15. Tavares P, Ravi N, Moura JJG, Le Gall J, Huang YH, Crouse BR, Johnson MK, Huynh BH, Moura I (1994) J Biol Chem 269:10504-10510

16. Emerson JP, Cabelli DE, Kurtz DM Jr (2003) Proc Natl Acad Sci USA 100:3802-3807 
17. Nivière V, Asso M, Weill CO, Lombard M, Guigliarelli B, Favaudon V, Houée-Levin C (2004) Biochemistry 43:808-818

18. Rodrigues JV, Saraiva LM, Abreu IA, Teixeira M, Cabelli DE (2007) J Biol Inorg Chem $12: 248-256$

19. Bonnot F, Houée-Levin C, Favaudon V, Nivière V (2010) Biochim Biophys Acta 1804: $762-767$

20. Rodrigues JV, Abreu IA, Cabelli D, Teixeira M (2006) Biochemistry 45:9266-9278

21. Emerson JP, Coulter ED, Cabelli DE, Phillips RS, Kurtz DM Jr (2002) Biochemistry $41: 4348-4357$

22. Archer M, Huber R, Tavares P, Moura I, Moura JJ, Carrondo MA, Sieker LC, LeGall J, Romao MJ (1995) J Mol Biol 251:690-702

23. Emerson JP, Coulter ED, Phillips RS, Kurtz DM Jr (2003) J Biol Chem 278:39662-39668

24. Rodrigues JV, Abreu IA, Saraiva LM, Teixeira M (2005) Biochem Biophys Res Commun 329:1300-1305

25. Grunden AM, Jenney FE Jr, Ma K, Ji M, Weinberg MV, Adams MW (2005) Appl Environ Microbiol 71:1522-1530

26. Auchère F, Sikkink R, Cordas C, Raleiras P, Tavares P, Moura I, Moura JJ (2004) J Biol Inorg Chem 9:839-849

27. Auchère F, Pauleta SR, Tavares P, Moura I, Moura JJ (2006) J Biol Inorg Chem 11:433444

28. Pagen CC, Moser CC, Chen X, Dutton PL (1999) Nature 402:47-52

29. Clay MD, Jenney FE Jr, Noh HJ, Hagedoom PL, George GN, Adams MWW, Johnson MK (2002) Biochemistry 41:9833-9841

30. Mathé C, Weill CO, Mattioli TA, Berthomieu C, Houée-Levin C, Tremey E, Nivière V (2007) J Biol Chem 282:22207-22216 
31. Pianzzola M J, Soubes M, Touati D(1996) J Bacteriol 178:6736-6742

32. McIver L, Leadbeater C, Campopiano DJ, Baxter RL, Daff SN, Chapman SK, Munro AW (1998) Eur J Biochem 257:577-585

33. Gray HB, Winkler JR (2003) Quart Rev Biophys 36:341-372

34. Kurtz DM Jr (2007) Dalton Trans 4115-4121 


\begin{tabular}{|c|c|c|}
\hline \multirow{2}{*}{ Electron transfert protein } & \multicolumn{2}{|c|}{$\begin{array}{c}\text { Initial velocity for SOR } \\
\text { reduction (units }\end{array}$} \\
\cline { 2 - 3 } & C13S mutant & WT \\
\hline No electron transfer protein & 451 & 10598 \\
\hline $\begin{array}{c}\text { Rubredoxin from Desulfoarculus } \\
\text { baarsii } \mathbf{( 5} \boldsymbol{\mu M})\end{array}$ & 10000 & 9731 \\
\hline $\begin{array}{c}\text { Rubredoxin from } \text { Clostridium } \\
\text { pasteurianum } \mathbf{( 5} \boldsymbol{\mu M})\end{array}$ & 9019 & 9471 \\
\hline Cytochrome c $(\mathbf{2 0} \boldsymbol{\mu M} / \mathbf{4 0} \boldsymbol{\mu M})$ & $2195 / 2480$ & $10824 / 10900$ \\
\hline
\end{tabular}

Table 1. Initial rates of reduction of the wild-type and C13S D. baarsii SOR proteins in the presence of Fpr and different electron transfer proteins. The initial velocity was measured by the reduction of the iron center II at $644 \mathrm{~nm}$ in a $100 \mu \mathrm{l}$ cuvette, in the presence of $10 \mathrm{mM}$ Tris- $\mathrm{HCl} \mathrm{pH} 7.6,100 \mu \mathrm{M}$ of SOR, $600 \mu \mathrm{M}$ of NADPH and $0.23 \mu \mathrm{g}$ of Fpr, at room temperature under anaerobic conditions.

${ }^{a} 1$ unit corresponds to the reduction of $1 \mathrm{nmol}$ of iron center II by min and by $\mathrm{mg}$ of Fpr. 


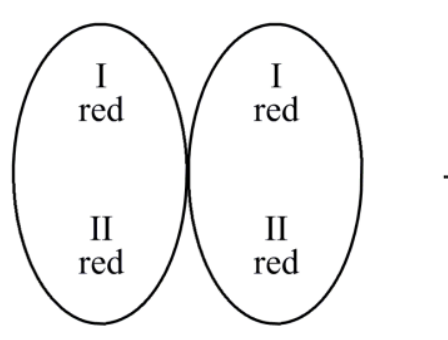

Fully reduced SOR

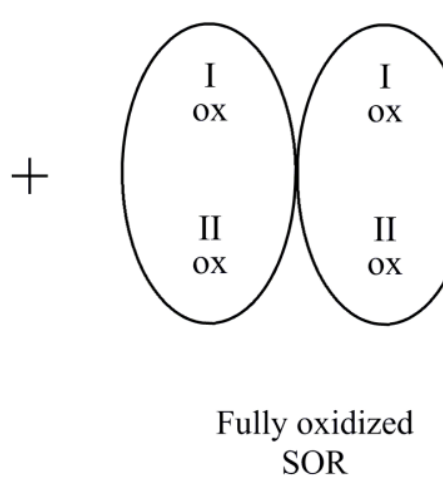

Semi reduced SOR

Scheme 1. Inter-molecular electron transfer mechanism between center I and center II of two different molecules of wild-type homodimeric SOR. 
Figure 1. Three-dimensional structure of the homodimeric SOR from Desulfoarculus baarsii (PDB code: 2JI1). Iron atoms are represented as red spheres, with residues coordinating them shown as gray sticks. 

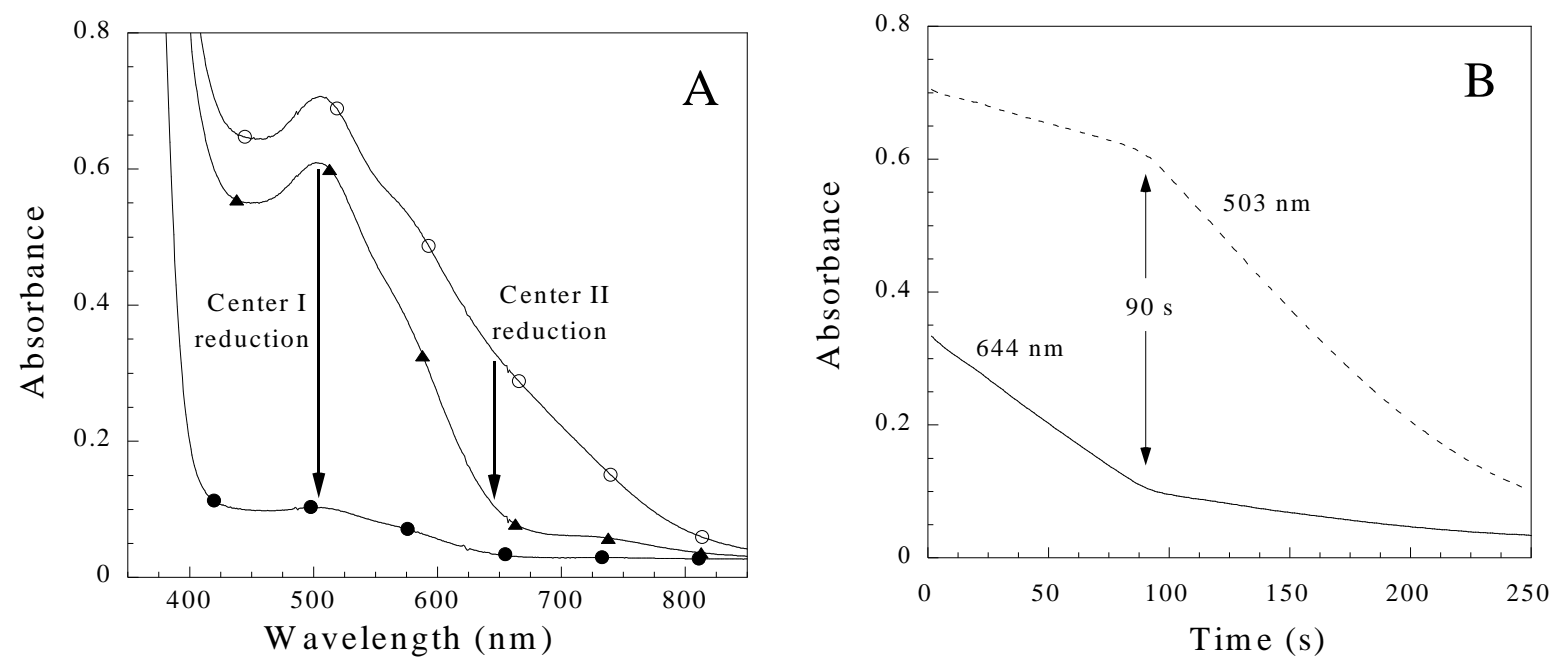

Figure 2. Sequential reduction process of the fully oxidized D. baarsii wild-type SOR by Fpr. A. The spectra were recorded in a $100 \mu \mathrm{l}$ spectrophotometric cuvette $(1 \mathrm{~cm}$ optical path) at 25 ${ }^{\circ} \mathrm{C}$, in the presence of $140 \mu \mathrm{M}$ of fully oxidized SOR, $0.7 \mu \mathrm{g}$ of Fpr, $800 \mu \mathrm{M}$ of NADPH and $25 \mathrm{mM}$ of Tris-HCl $\mathrm{pH}$ 7.6. (O), absorption spectrum of the fully oxidized SOR, at zero reaction time. ( $\boldsymbol{\Delta})$ absorption spectrum of the solution at $90 \mathrm{~s}$ reaction time, characteristic of the semi-reduced form of SOR. (•) absorption spectrum of the solution at $250 \mathrm{~s}$ reaction time, characteristic of the fully reduced form of SOR. B. Kinetic traces of the reduction processes showed in A, recorded at 503 (- -) and $644 \mathrm{~nm}(-)$. The breakdown of slopes observed at $90 \mathrm{~s}-$ reaction-time corresponds to the apparition of the spectrum of the semi-reduced form of SOR $(\boldsymbol{\Delta}$ in A.) 


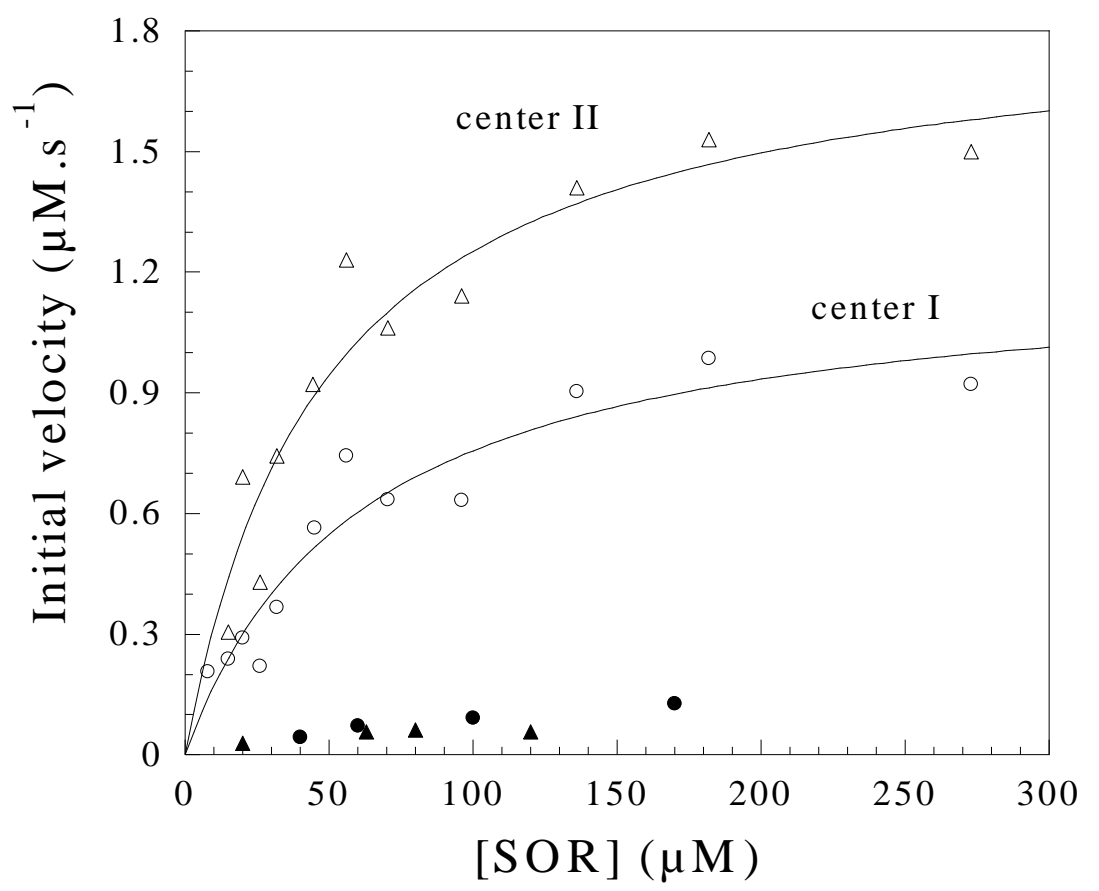

Figure 3. Initial rates for the reduction of center I and center II by Fpr as a function of SOR concentration. $(\circ)$ center I and $(\triangle)$ center II of the wild-type SOR from D. baarsii. ( $\Delta$ ) center II of the C13S SOR mutant from D. baarsii. (•) center II of the wild-type SOR from Treponema pallidum. The reductions were followed at $503 \mathrm{~nm}$ for center I and $644 \mathrm{~nm}$ for center II, at $25{ }^{\circ} \mathrm{C}$ under anaerobic conditions, in the presence of $800 \mu \mathrm{M}$ of NADPH, $0.7 \mu \mathrm{g}$ of Fpr, $25 \mathrm{mM}$ Tris-HCl pH 7.6 and different concentration of fully oxidized SORs. The lines were calculated for the best fits to a Michaelis-Menten model: $V_{i}=\left(V_{\max } \times[\mathrm{SOR}]\right) /\left(K_{m}+\right.$ [SOR]), with for the wild-type $D$. baarsii SOR center I, $K_{m}=61 \pm 15 \mu \mathrm{M}, V_{\max }=1.2 \pm 0.1$ $\mu \mathrm{M} \mathrm{s}^{-1}$ and for wild-type $D$. baarsii SOR center II, $K_{m}=48 \pm 11 \mu \mathrm{M}, V_{\max }=1.8 \pm 0.2 \mu \mathrm{M} \mathrm{s}^{-1}$. 

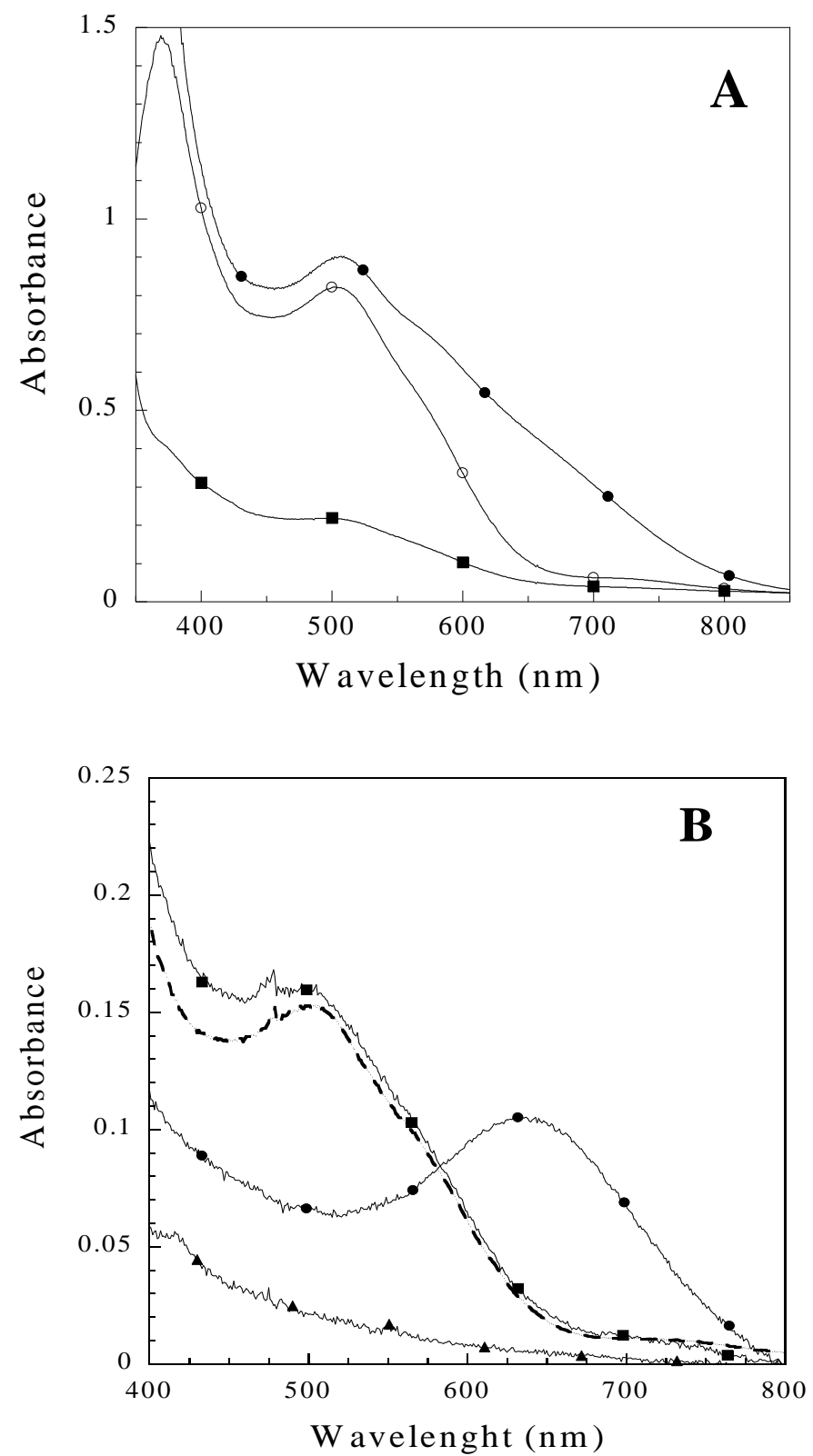

Figure 4. Electron transfer between the wild-type SOR center I and center II. A. Absorption spectra of D. baarsii wild-type SOR $(190 \mu \mathrm{M}$ in $10 \mathrm{mM}$ Tris-HCl, $\mathrm{pH}$ 7.6) in fully oxidized (•) or fully reduced ( $\mathbf{a})$ forms. (O) The resulting spectrum of the solution recorded immediately after the mixing of equal volumes of $(\bullet)$ with (घ), $190 \mu \mathrm{M}$ each. This spectrum superimposes to that of a solution of $190 \mu \mathrm{M}$ of semi-reduced form of wild-type SOR. B. Electron transfer between the reduced wild-type SOR center I and the oxidized C13S SOR mutant center II. 1 volume of $68 \mu \mathrm{M}$ of fully reduced wild-type SOR ( $\boldsymbol{\Delta})$ was mixed with 1 
volume of $68 \mu \mathrm{M}$ of fully oxidized C13S SOR mutant (•). (घ) shows the resulting spectrum of the solution recorded immediately after the mixing. This spectrum superimposes to that of a solution of $34 \mu \mathrm{M}$ of the semi-reduced form of wild-type SOR plus $34 \mu \mathrm{M}$ of the fully reduced C13S SOR mutant (dashed line). 


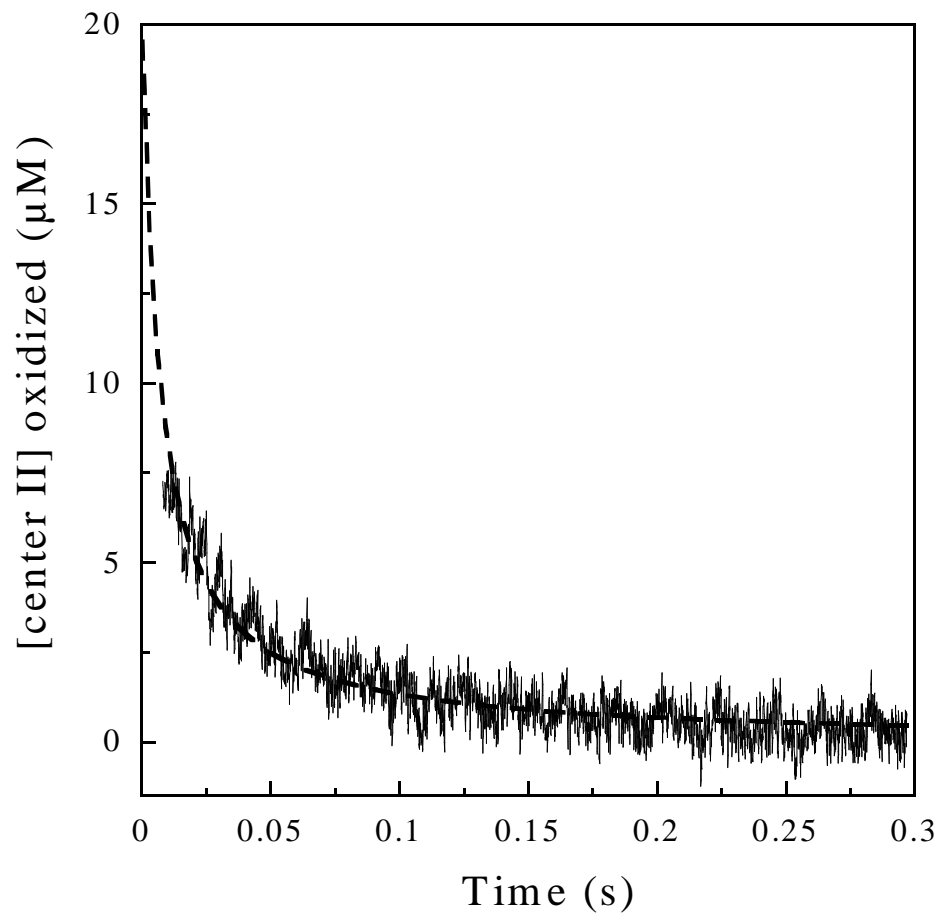

Figure 5. Stopped-flow kinetic trace recorded at $644 \mathrm{~nm}$ after the mixing of $50 \mu 1$ of fully oxidized SOR $(40 \mu \mathrm{M})$ with $50 \mu \mathrm{l}$ of fully reduced SOR $(40 \mu \mathrm{M})$, in $25 \mathrm{mM}$ Tris-HCl, pH 7.6, at $25^{\circ} \mathrm{C}$. The dashed line is the best fit to a second-order reaction model: [center $\left.\mathrm{II}_{\mathrm{ox}}\right]=$ $1 /\left(k t+1 /\left[\text { center } \mathrm{II}_{\mathrm{ox}}\right]_{\mathrm{i}}\right)$, where $k$ is the second order rate constant and $\left[\text { center } \mathrm{II}_{\mathrm{ox}}\right]_{\mathrm{i}}$ the initial concentration of oxidized center II, fixed at a value of $20 \mu \mathrm{M}$. A value of $k=7.0 \pm 0.1 \times 10^{6}$ $\mathrm{M}^{-1} \mathrm{~s}^{-1}$ was determined. 


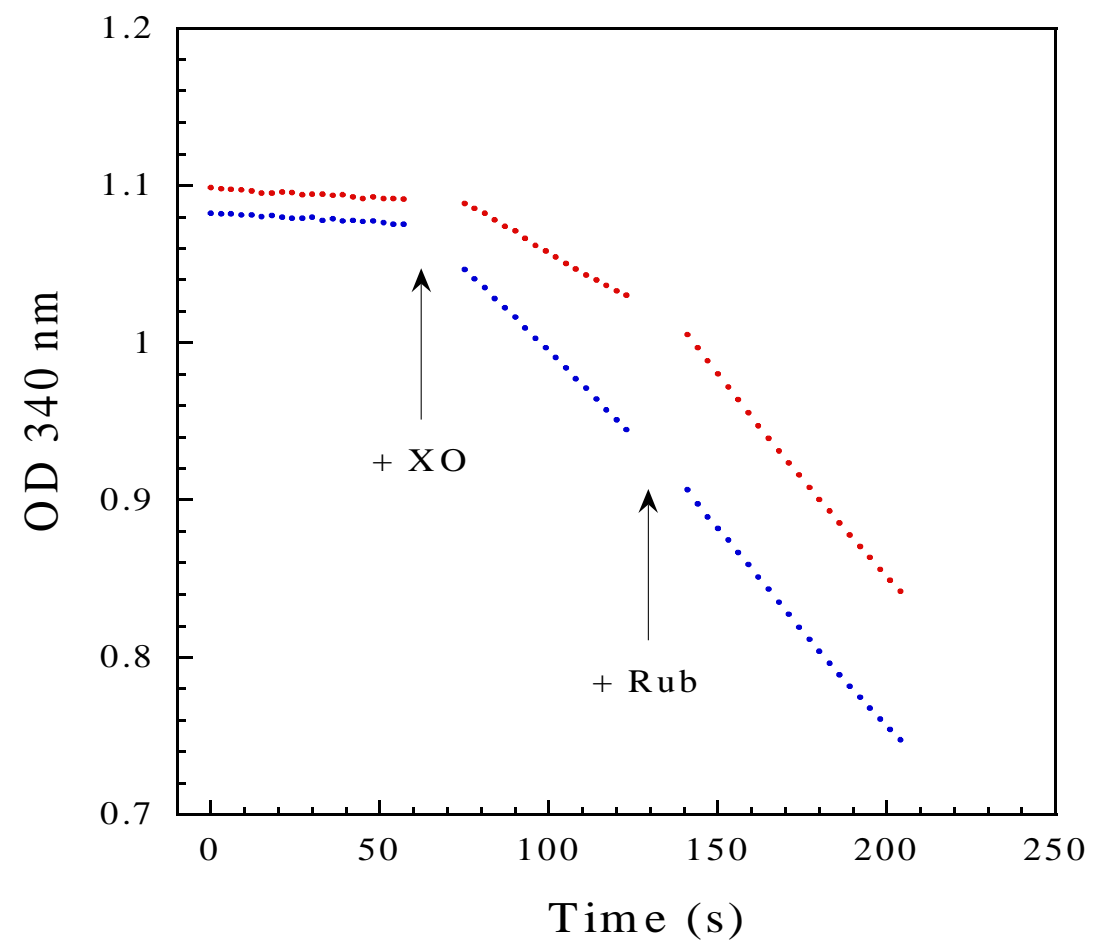

Figure 6. NADPH:superoxide oxidoreductase activities of the wild-type (blue) and C13S (red) SORs from D. baarsii. NADPH oxidation was followed at $340 \mathrm{~nm}$ in a $1 \mathrm{ml}$ spectrophotometric cuvette, containing $10 \mathrm{mM}$ Tris- $\mathrm{HCl} \mathrm{pH} 7.6,1 \mu \mathrm{M}$ of SOR, $200 \mu \mathrm{M}$ NADPH, 500 units/ml catalase, $500 \mu \mathrm{M}$ hypoxanthine and $1 \mu \mathrm{M}$ of Fpr, at room temperature. As indicated by the arrows, after $50 \mathrm{~s}$, a volume of xanthine oxidase (XO) producing a flux of superoxide of $22 \mu \mathrm{M} /$ min was added. After $120 \mathrm{~s}, 5 \mu \mathrm{M}$ of rubredoxin from $D$. baarsii (Rub) was added. 